\title{
EDITORIAL
}

\section{Nasal high-flow preoxygenation for endotracheal intubation in the critically ill patient? Con}

\author{
Jean-Luc Hanouz ${ }^{1,2^{*}}$, Jean Louis Gérard ${ }^{1,2}$ and Marc Olivier Fischer ${ }^{1,2}$
}

(C) 2019 Springer-Verlag GmbH Germany, part of Springer Nature

In 1959, Weitzner et al. published a cornerstone clinical study addressing the issue of arterial desaturation during apnoea following induction of general anaesthesia [1]. They showed that face-mask ventilation with $100 \%$ inhaled oxygen $\left(\mathrm{O}_{2}\right)$ before apnoea enabled the maintaining of arterial oxygen saturation up to $4 \mathrm{~min}$ in contrast to less than 1 min following ventilation with air. In 2019, preoxygenation is recommended for all patients before induction of anaesthesia and endotracheal intubation, and the end point of maximal preoxygenation is defined as an end tidal oxygen concentration $\left(\mathrm{ETO}_{2}\right) \geq 90 \%$ [2] Preoxygenation remains an area of research because hypoxaemia during upper airway management is still a concern in the operating room [2] and much more so in the intensive care unit where severe hypoxaemia and cardiac arrest have been reported to occur in $26 \%$ and $2.7 \%$, respectively, during orotracheal intubation of adult critically ill patients $[3,4]$. Furthermore, technological progress in anaesthesia machines, intensive care units ventilators, and oxygenation devices could improve the efficacy of preoxygenation and must be evaluated.

In the present issue of Intensive Care Medicine, Guitton et al. reports the results of a multicentre randomized controlled trial comparing high-flow nasal oxygen (HFNO) to bag-valve mask oxygenation for preoxygenation in non-severely hypoxemic adult patients requiring orotracheal intubation [5]. They show that preoxygenation with $\mathrm{HNFO}$ failed to improve the lowest $\mathrm{SpO}_{2}$ during intubation as compared to the "worst" method

*Correspondence: hanouz-jl@chu-caen.fr

2 Service Anesthésie Réanimation (niveau 6), CHU de Caen, Av Côte de Nacre, 14033 Caen Cedex, France

Full author information is available at the end of the article of preoxygenation in these patients (i.e. spontaneous breathing through a bag-valve mask).

Our first comment will recall that, in patients with acute respiratory, haemodynamic, and neurological failure requiring rapid airway control, increased oxygen consumption, decreased functional residual capacity, decreased cardiac output, loss of patient's cooperation, and increased risk of unanticipated difficult airway act synergistically to dramatically increase the time for maximal preoxygenation $[6,7]$, and the risk of severe hypoxemia during orotracheal intubation [3]. It has been convincingly shown in such patients that preoxygenation should be performed using non-invasive ventilation (NIV) with positive end expiratory pressure (PEEP). In adult patients with acute respiratory failure or hypoxaemia, preoxygenation through NIV with PEEP has been shown to maintain $\mathrm{SpO}_{2}$ and arterial partial pressure of $\mathrm{O}_{2}$ better than preoxygenation with a bag-valve mask $[8,9]$. In healthy patients, NIV with PEEP significantly reduced the time to obtain a maximal preoxygenation (i.e. $\mathrm{ETO}_{2} \geq 90 \%$ ) [10]. Finally, besides its specific pulmonary effects, NIV with PEEP has been shown to ensure an optimal preoxygenation through counteracting inward air leaks resulting from an ineffective face-mask seal [11].

Second, it is now the time in intensive care units to monitor the efficacy of preoxygenation (i.e. $\mathrm{ETO}_{2}$ ) and not only the lowest $\mathrm{SpO}_{2}$ during orotracheal intubation which is a serious adverse event related, at least in part, to inadequate preoxygenation [1]. Monitoring $\mathrm{ETO}_{2}$ is a standard of care in the operating room [2] because physiologic models and clinical studies have shown that the rate of oxyhaemoglobin desaturation is highly sensitive to the initial fraction of alveolar oxygen $[1,6,7]$. These models have also shown that hypovolaemia, anaemia,

\section{Springer}


reduced cardiac output, pulmonary ventilation-perfusion mismatch, hypoventilation and reduced alveolar volume contribute to shorten the onset of hypoxaemia during apnoea [4]. All these variables can contribute to the high rate of severe hypoxaemia and cardiac arrest associated with orotracheal intubation in adult critically ill patients $[3,4]$.

High-flow nasal $\mathrm{O}_{2}$ allows for delivering up to $60 \mathrm{l} \mathrm{min}^{-1}$ of heated and humidified gas with $21-100 \%$ inspired $\mathrm{O}_{2}$ fraction. Over the past decade, HFNO has been shown to improve oxygenation, dyspnoea, and comfort in acute hypoxaemic respiratory failure as compared to conventional oxygen therapy [12]. However, the effectiveness of HFNO depends on the following mandatory conditions: the patient must breathe with his mouth hermetically closed, the patient's peak inspiratory flow must remain lower than $601 \mathrm{~min}^{-1}$, and the size of the nasal cannula must be adapted to the patient's nostril size to limit inward air pollution. If these conditions are fulfilled, HFNO decreases resistance of the upper airway, decreases work of breathing, induces a moderate positive expiratory nasopharyngeal pressure, and reduces oxygen dilution with room air [12]. Unfortunately, a patient with acute respiratory or haemodynamic failure breathes with his mouth largely open in order to decrease inspiratory flow resistance. Furthermore, to cope with the mismatch between $\mathrm{O}_{2}$ demand and supply, respiratory pattern changes and the peak nasal and oral inspiratory flow can be as high as 110 and $2801 \mathrm{~min}^{-1}$, respectively [13]. In such cases, inward air dilution is unavoidable during
HFNO resulting in a significant decrease in the inspired concentration of $\mathrm{O}_{2}$ which precludes maximal preoxygenation [10]. We recently showed in healthy volunteers that $\mathrm{HFNO}$ resulted in a lower and highly variable $\mathrm{ETO}_{2}$ than preoxygenation through a face mask [14]. After 3 and 6 min of preoxygenation through HFNO, only $4 \%$ and $46 \%$ of volunteers had an $\mathrm{ETO}_{2} \geq 90 \%$, respectively.

Together, these data clearly show that HFNO is not a reliable method of preoxygenation. First, it is impossible to closely monitor the $\mathrm{ETO}_{2}$ which is the most useful index of maximal preoxygenation. Second, data show that the $\mathrm{ETO}_{2}$ obtained following preoxygenation with HFNO is lower than $90 \%$ and highly variable. We must never forget that the rate of oxyhaemoglobin desaturation is highly sensitive to the initial alveolar fraction of oxygen. Third, the mandatory conditions required to ensure the effectiveness of HFNO (mouth closed, peak inspiratory flow $<601 \mathrm{~min}^{-1}$ ) may not be fulfilled in critically ill patients with acute respiratory, haemodynamic, and neurologic failure.

Nevertheless, the advantage of HFNO is in providing an efficient apnoeic oxygenation [12]. We suggest that it should be used as an adjunct to preoxygenation through NIV, as recently reported by Jaber et al. [15]. This study suggests that a combination of preoxygenation through NIV with apnoeic oxygenation through HFNO resulted in a significantly higher minimal $\mathrm{SpO}_{2}$ during intubation than preoxygenation with NIV alone.

In conclusion, the higher the measured $\mathrm{ETO}_{2}$, the longer will be the apnoea without desaturation. We

Table 1 Modifiable safety factors to prevent respiratory complications during orotracheal intubation in intensive care unit

\begin{tabular}{ll}
\hline Modifiable factors & Effect \\
\hline Optimizing patient's environment & Call for help, presence of at least one skilled practitioner \\
& Difficult intubation protocol adopted by the medical and paramedical staff \\
& Difficult intubation specific devices ready to use \\
Positioning the patient & $30^{\circ}$ head-up inclination \\
Specific monitoring during the procedure & Continuous inspired and expired concentration of oxygen (preoxygenation) \\
& Continuous inspired and expired concentration of carbon dioxide (tube placement) \\
Maximising inspired oxygen concentration & Inspired concentration of oxygen is $100 \%$ \\
& High level of fresh gas flow $\left(\geq 15\right.$ I min ${ }^{-1}$ ) \\
& Select the best face mask according to the patient's face \\
& Avoid leaks around the face mask \\
& Counteract air pollution using a positive end expiratory pressure \\
Method for preoxygenation & Non-invasive ventilation with positive end expiratory pressure if possible \\
Duration of preoxygenation & Until end tidal oxygen $\geq 90 \%$ \\
If end tidal oxygen $<90 \%$,anticipate a high probability of rapid desaturation \\
During intubation & Apnoeic oxygenation through high-flow nasal oxygen \\
& Optimise laryngeal view by external laryngeal manipulation \\
Tracheal intubation confirmation & Maintenance of oxygenation is the priority \\
Reporting the procedure & Visual confirmation of the tube between vocal cords \\
\hline
\end{tabular}


have summarized some modifiable factors (Table 1) to improve the safety of orotracheal intubation in the ICU.

"A good beginning, makes a good ending".

\author{
Author details \\ ${ }^{1}$ Normandie University, UNICAEN, Service Anesthésie Réanimation, CHU de \\ Caen, Avenue de la Côte de Nacre, CS 30001, 14000 Caen, France. ${ }^{2}$ Ser- \\ vice Anesthésie Réanimation (niveau 6), CHU de Caen, Av Côte de Nacre, \\ 14033 Caen Cedex, France.
}

\section{Compliance with ethical standards}

\section{Conflicts of interest}

The authors declare that they have no conflict of interest.

\section{Ethical approval}

An approval by an ethics committee was not applicable.

\section{Publisher's Note}

Springer Nature remains neutral with regard to jurisdictional claims in published maps and institutional affiliations.

Received: 28 January 2019 Accepted: 4 February 2019

Published online: 12 February 2019

\section{References}

1. Weitzner SW, King BD, Ikezono E (1959) The rate of arterial oxygen desaturation during apnea in humans. Anesthesiology 20:624-627

2. Langeron O, Bourgain JL, Francon D et al (2018) Difficult intubation and extubation in adult anaesthesia. Anaesth Crit Care Pain Med. 37:639-651. https://doi.org/10.1016/j.accpm.2018.03.013

3. Jaber S, Amraoui J, Lefrant J-Y et al (2006) Clinical practice and risk factors for immediate complications of endotracheal intubation in the intensive care unit: a prospective, multiple-center study. Crit Care Med 34:23552361. https://doi.org/10.1097/01.ccm.0000233879.58720.87

4. De Jong A, Rolle A, Molinari N et al (2018) Cardiac arrest and mortality related to intubation procedure in critically ill adult patients: a multicenter cohort study. Crit Care Med 46:532-539. https://doi.org/10.1097/ ccm.0000000000002925
5. Guitton C, Ehrmann S, Volteau C et al (2019) Nasal high-flow preoxygenation for endotracheal intubation in the critically ill patient: a randomized clinical trial. Intensive Care Med. https://doi.org/10.1007/s00134-01905529-w

6. Farmery AD, Roe PG (1996) A model to describe the rate of oxyhaemoglobin desaturation during apnoea. Br J Anaesth 76:284-291

7. Pehböck D, Wenzel V, Voelckel W et al (2010) Effects of preoxygenation on desaturation time during hemorrhagic shock in pigs. Anesthesiology 113:593-599. https://doi.org/10.1097/aln.0b013e3181e73f07

8. Baillard C, Fosse JP, Sebbane M et al (2006) Noninvasive ventilation improves preoxygenation before intubation of hypoxic patients. Am J Respir Crit Care Med 174:171-177. https://doi.org/10.1164/rccm.20050 9-1507oc

9. Jaber S, Jung B, Corne P et al (2010) An intervention to decrease complications related to endotracheal intubation in the intensive care unit: a prospective, multiple-center study. Intensive Care Med 36:248-255. https ://doi.org/10.1007/s00134-009-1717-8

10. Hanouz JL, Lammens S, Tasle M, Lesage A, Gérard JL, Plaud B (2015) Preoxygenation by spontaneous breathing or noninvasive positive pressure ventilation with and without positive end-expiratory pressure: a randomised controlled trial. Eur J Anaesthesiol 32:881-887. https://doi. org/10.1097/eja.0000000000000297

11. Hanouz JL, Le Gall F, Gérard JL, Terzi N, Normand H (2018) Non-invasive positive-pressure ventilation with positive end-expiratory pressure counteracts inward air leaks during preoxygenation: a randomised crossover controlled study in healthy volunteers. Br J Anaesth 120:868-873. https:// doi.org/10.1016/j.bja.2017.12.002

12. Renda T, Corrado A, Iskandar $\mathrm{G}$ et al (2018) High-flow nasal oxygen therapy in intensive care and anaesthesia. Br J Anaesth 120:18-27. https ://doi.org/10.1016/j.bja.2017.11.010

13. Tsounis M, Swart KMA, Georgalas C, Markou K, Menger DJ (2014) The clinical value of peak nasal inspiratory flow, peak oral inspiratory flow, and the nasal patency index. Laryngospcope 124:2665-2669. https://doi. org/10.1002/lary.24810

14. Hanouz JL, Lhermitte D, Gérard JL, Fischer MO (2019) Comparison of preoxygenation using spontaneous breathing through face mask and high-flow nasal oxygen. A prospective randomized crossover controlled study in healthy volunteers. Eur J Anaesthesiol. https://doi.org/10.1097/ eja.0000000000000954 [(Epub ahead of print) in press]

15. Jaber S, Monnin M, Girard M et al (2016) Apnoeic oxygenation via highflow nasal cannula oxygen combined with non-invasive ventilation preoxygenation for intubation in hypoxaemic patients in the intensive care unit: the single-centre, blinded, randomised controlled OPTINIV trial. Intensive Care Med 42:1877-1887. https://doi.org/10.1007/s0013 4-016-4588-9 